\title{
Effects of Cryptomeria japonica bark on circadian variations in lymphocytes and neutrophils in sheep
}

\author{
S. Oda ${ }^{1}$, M. Miyashita, Y. Iwabuchi, K. Kogusuri, H. Suzuki, \\ T. Tamura and Y. Nakashima
}

Laboratory of Animal Nutrition and Physiology,

Department of Agro-bioscience, Iwate University

3-18-8 Ueda, Morioka 020-8550, Japan

\begin{abstract}
The effect of bark from Cryptomeria japonica trees on circadian variations in lymphocyte and neutrophil counts in sheep was studied. Hay supplemented with bark caused decreased leukocyte counts in peripheral blood compared with hay alone. Percentages of lymphocytes were slightly increased, and neutrophils were slightly decreased compared to controls. Plasma NEFA concentrations with bark and hay were also lower than those with hay alone. These results suggest that feed supplemented with bark may increase parasympathetic activity in sheep.
\end{abstract}

KEY WORDS: lymphocyte, neutrophil, sheep, bark, circadian variation, NEFA

\section{INTRODUCTION}

Bark represents an important biomass resource, comprising about 10-15\% of total tree weight. However, bark is typically not considered useful for animal fodder due to high lignin content, low nutritional value and low palatability. Some animals, such as sheep, do not appear averse to eating bark.

The sympathetic nervous system is easily activated by numerous factors, including stress. Granulocytosis occurs with increased sympathetic activity, whereas lymphocytosis is seen with increased parasympathetic activity in humans (Fukuda et al., 1996). The present study examined the effects of bark as a feed on metabolites and circadian variations in blood cell counts in sheep.

\footnotetext{
${ }^{1}$ Corresponding author: e-mail: soda@iwate-u.ac.jp
} 


\section{MATERIAL AND METHODS}

\section{Animals and experimental procedure}

Five sheep ( $41 \pm 12.1 \mathrm{~kg}$ body weight) were included in this pilot study. The sheep were housed individually in metabolic cages. The sheep was given the following treatments for 4 weeks in the following sequence.

1. Mixed hay treatment. The sheep were offered a timothy hay and orchard grass mix at $2 \%$ of BW kg/day in a single meal at 12.00 .

2. Mixed hay and bark treatment. Each sheep was offered bark (200 g/day) from Cryptomeria japonica trees with the mixed hay once daily.

Any remaining feed, primarily bark, was removed and weighed the next day. Water was available ad libitum. Blood sampling was performed on the final day of each treatment.

At least $1 \mathrm{~h}$ before the experiment, a polyethylene catheter for blood sampling was inserted into the jugular vein and serial blood sampling was performed from 11.00 to 10.00 the following day. Blood samples $(2 \mathrm{ml})$ were drawn using a syringe containing heparin, and blood cell counts for leukocytes and erythrocytes were immediately performed twice using an automatic haematocytometer. The remaining blood was centrifuged at $4^{\circ} \mathrm{C}$ as soon as possible. Plasma levels of glucose, NEFA, BUN and $\mathrm{NH}_{3}$ were determined using an automatic analyser. Blood smears were prepared and percentages of peripheral blood lymphocytes and granulocytes were counted using Giemsa staining.

\section{Statistical analysis}

Mean values and standard errors of the mean were calculated. Data were assigned to six 4-h periods. Significant differences between periods were analysed using analysis of variance and the Tukey test at the 0.05 and 0.01 levels. Statistical differences between hay+bark and hay only within the same period were processed using Student's t-test.

\section{RESULTS}

Mean 4-h leukocyte counts in sheep fed hay only or hay+bark are indicated in Table 1. Mean leukocyte counts before feeding were $3193 \pm 241$ cells $/ \mu 1$ for controls and $2855 \pm 198$ cells/ $\mu$ f for hay+bark, respectively, representing a significant difference $(\mathrm{P}<0.05)$. Each mean 4 -h value in the hay+bark group was significantly lower than the corresponding control value, except for the 8.0012.00 value. No clear circadian rhythm in leukocytes was observed.

Percentages of lymphocytes and neutrophils during $24 \mathrm{~h}$ are also showed in Table 2. 
Table 1. Circadian variations in leukocyte counts in sheep, cells $/ \mu 1$

\begin{tabular}{lccc}
\hline Time, $\mathrm{h}$ & Mixed hay & Mixed hay + bark & \\
\hline Before feeding & $3193 \pm 241$ & $2855 \pm 198$ & $\mathrm{P}<0.05$ \\
$12.00-16.00$ & $3370 \pm 255$ & $2986 \pm 275$ & $\mathrm{P}<0.01$ \\
$1600-20.00$ & $3763 \pm 329$ & $2879 \pm 200$ & $\mathrm{P}<0.05$ \\
$20: 00-24.00$ & $2966 \pm 392$ & $2472 \pm 247$ & $\mathrm{P}<0.01$ \\
$00.00-04: 00$ & $3119 \pm 245$ & $2667 \pm 301$ & $\mathrm{P}<0.05$ \\
$04.00-08.00$ & $2731 \pm 243$ & $2372 \pm 316$ & $\mathrm{P}<0.05$ \\
$08.00-12.00$ & $3003 \pm 510$ & $2833 \pm 219$ & $\mathrm{NS}$ \\
\hline
\end{tabular}

Table 2. Percentages of lymphocytes and neutrophils over $24 \mathrm{~h}$ in peripheral sheep blood

\begin{tabular}{lccccc}
\hline \multirow{2}{*}{ Time, $\mathrm{h}$} & \multicolumn{2}{c}{ Lymphocytes } & & \multicolumn{2}{c}{ Neutrophils } \\
\cline { 2 - 3 } \cline { 5 - 6 } \cline { 5 - 6 } $\begin{array}{l}\text { Before } \\
\text { feeding }\end{array}$ & mixed hay & mixed hay + bark & & mixed hay & mixed hay + bark \\
12:00-16:00 & $48.3 \pm 3.0$ & $59.4 \pm 2.7^{* *}$ & & $43.9 \pm 3.1$ & $34.5 \pm 3.5$ \\
16:00-20:00 & $49.0 \pm 3.3$ & $59.1 \pm 2.7^{*}$ & & $42.8 \pm 5.8$ & $35.1 \pm 2.7$ \\
20:00-24:00 & $45.4 \pm 5.2$ & $54.0 \pm 3.6$ & & $45.9 \pm 6.8$ & $3.1 \pm 1.9$ \\
00:00-04:00 & $45.1 \pm 3.7$ & $59.3 \pm 3.6^{* *}$ & & $44.6 \pm 5.8$ & $32.6 \pm 4.5$ \\
04:00-08:00 & $47.2 \pm 1.3$ & $54.1 \pm 4.6$ & & $41.8 \pm 2.8$ & $39.0 \pm 4.7$ \\
08:00-12:00 & $51.2 \pm 3.9$ & $64.8 \pm 2.9^{*}$ & & $38.8 \pm 4.8$ & $28.5 \pm 2.5$ \\
\hline
\end{tabular}

* $\mathrm{P}<0.05$ vs mixed hay, ${ }^{* *} \mathrm{P}<0.01$ vs mixed hay

No significant differences in plasma glucose, $\mathrm{BUN}$ or $\mathrm{NH}_{3}$ concentrations were identified between hay only and hay+bark feeds. Plasma NEFA concentrations were significantly lower for sheep given hay+bark than for those given hay alone.

\section{DISCUSSION}

The present study identified no clear circadian variations in lymphocyte or neutrophil counts in sheep, but sheep fed bark from C. japonica trees had lower leukocyte counts in peripheral blood compared with controls. Compared to controls, percentages of lymphocytes were slightly increased and percentages of neutrophils were slightly reduced. Abo et al. (1981) reported that percentages of lymphocytes display a single fluctuation during the 24-h sleep-wake cycle in humans. Granulocytosis is seen with increased sympathetic activity at high pressure, whereas lymphocytosis is seen with increased parasympathetic activity at low pressure in humans (Fukuda et al., 1996). These findings suggest that bark may play some role in 
autonomic nervous activity in sheep, as plasma NEFA concentrations were lower in sheep offered bark than in controls.

Variations in cell counts and numbers of mononuclear $\mathrm{T}$ and $\mathrm{B}$ cells are reported to be inversely related to plasma cortisol levels (Abo et al., 1981). However, more detailed studies are needed to explain the relationships between autonomic nervous activity and blood cell counts in sheep or ruminants.

\section{CONCLUSIONS}

Bark from Cryptomeria japonica decreased leukocyte counts in peripheral sheep blood compared with controls, whereas percentages of lymphocytes were slightly increased and percentages of neutrophils were slightly lower than in controls. Plasma NEFA concentrations with hay+bark were also lower than those with hay alone. These data suggest that feed supplemented with bark may increase parasympathetic activity in sheep.

\section{REFERENCES}

Abo T., Kawate T., Itoh K., Kumagai K., 1981. Studies on the bioperiodicity of the immune response. J. Immnol. 126, 1360-1363

Fukuda M., Moroda T., Toyabe S., Iiai T., Kawachi Y., Takahashi-Iwanaga H., Iwanaga T., Okada M., Abo T., 1996. Granulocytosis induced by increasing sympathetic nerve activity contributes to the incidence of acute appendicitis. Biomed. Res. 17, 171-181 